\title{
Physical Demands in Three Different Basketball Competitions Played By the Same Under-18 Players
}

\author{
Hugo Salazar ${ }^{1,2}$, Franc García ${ }^{1,3}$, Luka Svilar ${ }^{4}$, Julen Castellano ${ }^{1}$
}

Affiliations: 'University of Basque Country (UPV/EHU), Faculty of Education and Sport, Vitoria-Gasteiz, Spain, ${ }^{2}$ Saski Baskonia SAD, Physical Performance Department, Vitoria-Gasteiz, Spain, ${ }^{3}$ Fútbol Club Barcelona, Sports Performance Area, Barcelona, Spain, ${ }^{4}$ BC Unics, Physical Performance Department, Kazan, Russia

Correspondence: H. Salazar, University of Basque Country, Faculty of Education and Sport, Carretera de Lasarte, 71, 01007, Vitoria-Gasteiz, Spain, Email: hsalazar@baskonia.com

\begin{abstract}
The goal of this study was to compare the physical demands of the same team in three different basketball competitions (EBA league (EBA), U18 regional league (U18L), and a U18 international tournament (U18T)) during the same season. Data from eleven U18 players (age: $16.92 \pm 0.67$ years) were collected using inertial movement units. As external load variables, Player Load (PL), accelerations (ACC), decelerations (DEC), changes of direction (COD), and jumps (JUMP) were expressed in their total $(\mathrm{t})$ and high intensity $(\mathrm{h})$ values. The analysis of variances (ANOVA) and effect size (ES, Cohen's d) with their respective $90 \%$ confidence intervals were applied to identify differences between the competitions. U18T showed the highest values in PL, tACC, tDEC, hDEC, tCOD, tJUMP, and hJUMP (small to moderate ES). However, the hACC and hCOD values were greater in EBA (small ES) than in U18L and U18T. In conclusion, all three competitions presented different external load demands for the same group of players. This data could help basketball coaches to optimize the training process based on the competition in which their team plays. Furthermore, data could also indicate the most suitable competition for players' development.
\end{abstract}

Keywords: basketball, inertial movement analysis, team sport, monitoring, training load

@MJSSMontenegro

PHYSICAL DEMANDS OF THREE DIFFERENT COMPETITIONS

http://mjssm.me/?sekcija=article\&artid=224

Cite this article: Salazar, H., Garcia, F., Svilar, L., \& Castellano, J. (2021). Physical Demands in Three Different Basketball Competitions Played By the Same Under-18 Players. Montenegrin Journal of Sports Science and Medicine, 10(2), 59-64. doi: 10.26773/mjssm.210909

\section{Introduction}

Basketball is a team-based and opposition sport in which high-intensity actions, such as accelerations, changes of direction, and jumps, are combined with moments of pause during games (Stojanovic et al., 2018). It is important to quantify the physical demands experienced by players during different basketball competitions to improve the process of players' sports growth from lower categories until professionalism (Petway et al., 2020).

Most clubs have programmes to select and develop the tal- ent of young basketball players. Through training, their final purpose is to prepare potential players for the training and competition demands of professional basketball (Sotiriadou \& Shilbury, 2013). Various strategies have been proven to be successful during the development of sports talent, such as the theories of 10 years and deliberate practice (Ericsson et al., 1993; Newell \& Rosenbloom, 1981). However, there are critical moments in the maturation process at which development can be greatly stimulated if the players engage with situations 
that require them to perform at their optimal level (Berry et al., 2008). These situations can range from applying the appropriate training stimulus at a certain age to being able to face the best possible rival to demanding the greatest technical, tactical, and physical requirements.

At present, the competition model that exists in Spain allows players who are still in training age categories (Junior/ U18) to participate in professional or semi-professional competitions at the national level. This is a structured development model forming part of a long-term strategic one (Calleja-González et al., 2016). However, there are challenges in the physical demands that players must overcome to compete at the professional level. As the league level increases, players are required to perform a greater number of high-intensity and moderate-intensity actions than in the minor leagues (Scanlan et al., 2011), which suggests planning long-term training. Furthermore, players need to be prepared for a greater demand for high-intensity moments and shorter breaks between situations (Ferioli et al., 2020). In addition to higher physical demands, professional competitions also show increased technical and tactical demands and a higher percentage of effectiveness to which junior players must adapt (Conte et al., 2017).

Differences between U18, professional, and senior players have been described (Trapero et al., 2020). However, all studies compared different samples (one of the senior players and the other of under-18 players). Therefore, there is a comparative bias due to a multitude of factors, such as the game model, the rival, the player's physical characteristics, and the refereeing of the match (Fox et al., 2019). To the authors' knowledge, there is no study comparing the same players competing at different levels. This study would provide valuable information to assess the differences that may exist in basketball physical demands more accurately.

This work aimed to describe and compare the physical demands of the same team of basketball players during three different competitions completed in the same season. The results could help to optimize the training process of players simultaneously participating in different competitions. Moreover, this investigation could also aid in understanding the optimal competition for the players to receive adequate physical stimulation during training.

\section{Methods}

\section{Design}

Data were collected in three different competitions: EBA League (EBA, $4^{\text {th }}$ senior category of Spanish basketball); Regional League of under 18 players (U18L); international tournament of the under-18 category (U18T). Two leagues (EBA and U18L) were analysed from September to March, corresponding to the first part of the competitive period. The U18T took place between the $3^{\text {rd }}$ and $6^{\text {th }}$ of January; four games were played in three days between junior international players. All games of the three competitions were monitored through inertial movement units (IMU). In total, 32 matches were recorded (15 from EBA, 13 from U18L, and four from U18T).

\section{Participants}

Eleven players in the U18 age-level (age: $16.92 \pm 0.67$ years) participated in the study. Before the study, the anthropometric data for each player were collected following the standards of technical measurement recommended by the International Working Group of Kinanthropometry, ISAK (Table 1).

Table 1. Anthropometric values of the players participating in the study. Total values are presented as mean \pm standard deviation (SD)

\begin{tabular}{|c|c|c|c|c|c|c|}
\hline Participants & Height (cm) & Weight (kg) & $\mathrm{BMI}\left(\mathrm{kg} / \mathrm{m}^{-2}\right)$ & Sum 8 Skinfolds (mm) & Body fat (\%) & Muscle mass (\%) \\
\hline Player 1 & 195.5 & 98.4 & 25.7 & 66.5 & 8.1 & 50.6 \\
\hline Player 2 & 185.0 & 76.1 & 22.2 & 57.6 & 6.6 & 49.5 \\
\hline Player 3 & 186.6 & 69.1 & 19.8 & 45.6 & 7.5 & 49.1 \\
\hline Player 4 & 209.0 & 97.6 & 22.3 & 103.1 & 13.3 & 41.6 \\
\hline Player 5 & 200.1 & 84.0 & 21.0 & 52.0 & 5.8 & 48.7 \\
\hline Player 6 & 203.0 & 75.1 & 18.2 & 36.0 & 3.2 & 51.0 \\
\hline Player 7 & 200.1 & 74.7 & 18.6 & 46.5 & 4.9 & 48.4 \\
\hline Player 8 & 202.5 & 91.7 & 22.4 & 65.0 & 7.8 & 49.0 \\
\hline Player 9 & 201.7 & 84.6 & 20.9 & 71.0 & 9.3 & 46.0 \\
\hline Player 10 & 211.6 & 100.7 & 22.5 & 65.0 & 6.1 & 49.2 \\
\hline Player 11 & 202.0 & 76.2 & 18.6 & 46.2 & 4.7 & 42.6 \\
\hline Team average & $200.9 \pm 7.2$ & $84.4 \pm 11.1$ & $21.1 \pm 2.2$ & $58.5 \pm 18.1$ & $6.9 \pm 2.6$ & $48.3 \pm 2.4$ \\
\hline
\end{tabular}

The anthropometric material used was previously approved and calibrated: wall height rod (precision, $1 \mathrm{~mm}$ ); Tanita scale (precision, $100 \mathrm{~g}$ ); Rosscraf metric metal tape, which was narrow and inextensible (precision, $1 \mathrm{~mm}$ ); Holtain small bone diameter pachymeter (precision, $1 \mathrm{~mm}$ ); Cescorf2 calliper (precision, $0.5 \mathrm{~mm}$ ); complementary material (demographic pencil to mark the subject); and anthropometric bench of $40 \times$ $50 \times 30 \mathrm{~cm}$. Carter (1982) and Lee's (Lee et al., 2000) formulas were used to calculate fat and muscle percentages. All players belonged to the same team of a Euroleague (European first division) and ACB (Spanish first division) academy in Spain and simultaneously participated in the three competitions. Players completed a total of five to six weekly basketball training sessions, along with two to three strength-training sessions and two games each week. Each player was informed about the study requirements by the club, and each one gave his written and verbal consent. Moreover, all the ethical procedures used in this study were in accordance with the Declaration of Helsinki, Fortaleza update (Harris \& Atkinson, 2015) and were approved by the Basque Country University Ethics Committee.

\section{External load variables}

As in previous studies in basketball (Svilar et al., 2018; Salazar et al., 2020), a combination of variables was used to 
estimate the frequency of total and high-intensity actions. This strategy provided more detailed information on the physical demands of the players (Fox et al., 2020). Inertial variables included PlayerLoadTM (PL); changes of direction ((COD), directions from $-135^{\circ}$ to -45 to the left, and from $45^{\circ}$ to 135 to the right); decelerations ((DEC), direction from $135^{\circ}$ to $\left.135^{\circ}\right)$; accelerations ( $(\mathrm{ACC})$, directions from $-45^{\circ}$ to $45^{\circ}$ ); and jumps (JUMP). The PL was recorded by the accelerometer of the inertial devices whose sampling frequency is $100-\mathrm{Hz}$, and it is represented by the square root of the changes in acceleration in the three spatial axes (Nicolella et al., 2018). The variables COD, DEC, ACC, and JUMP are shown in their total $(\mathrm{t})$ and high intensity $(\mathrm{h})$ values. We established the threshold at $\pm 3 \mathrm{~m} \cdot \mathrm{s}-2$ for COD, DEC, and ACC, and at > $40 \mathrm{~cm}$ for JUMP. All data were relativized to the total minutes in the field of each player (min-1), excluding rest times and time-outs. This allowed a comparison regardless of the difference in minutes played by each player during the matches analysed.

\section{Procedures}

All official matches were based on FIBA basketball rules, with four quarters of 10 minutes of live time, two minutes of rest between quarters, and 15 between halves. We used inertial devices to monitor external load during matches (Catapult T6, Catapult Innovations, Melbourne, Australia). This technology had been previously validated in small field indoor sports (Luteberget et al., 2018). Devices were placed in the players' scapular area through a custom vest and were turned on 30 minutes before the matches started. Players were familiar with the devices as they used them in their day-to-day training at the club. After their recording, all data was exported through specific software (OpenField version 2.3.1, Catapult Innovations, Melbourne, Australia). Afterwards, the data was processed in an Excel workbook for Mac (Microsoft Excel version 16, Microsoft Corporation, Redmond, WA, USA).

\section{Statistical analysis}

All descriptive data are shown as mean \pm standard deviation (SD). The normality of the data distribution and the sphericity was confirmed using the Shapiro-Wilk test and the test of Levene for the equality of variances, respectively. The differences between groups were examined using a statistical analysis of variances (ANOVA) and taking the "competition" dimension (EBA, U18L and U18T) as a factor. Statistical significance was established at $\mathrm{p}<0.05$. Subsequently, effect sizes (ES) were calculated using Cohen's d with their respective confidence intervals of $90 \%$. The ES were interpreted based on the following thresholds: $<0.2$, trivial; 0.2-0.6, small; 0.6-1.2, moderate; 1.2-2.0, long; and > 2.0, exceptionally long (Batterham and Hopkins, 2006). All of the analyses were performed by using the Microsoft Excel software for Mac (Microsoft Excel version 16, Microsoft Corporation, Redmond, WA, USA) and the free statistical package JASP version 0.9.2 (University of Amsterdam, https: // jasp-stats.org/).

\section{Results}

Table 2 shows the absolute values of all external load variables analysed for each competition (EBA, U18L, and U18T). The highest values for PL, tCOD, tACC, DEC component, and JUMP variables were found in U18T competition. EBA competition showed the greatest demands in hCOD and hACC.

Table 2. Mean \pm standard deviation (SD) for each of the external load variables in the three competitions analysed: EBA League (EBA), U18 autonomic league (U18L) and international tournament (U18T)

\begin{tabular}{|c|c|c|c|c|}
\hline & EBA & U18L & U18T & $p$ \\
\hline PL (ua. $\mathrm{min}^{-1}$ ) & $11.02 \pm 0.93$ & $11.08 \pm 1.09$ & $11.39 \pm 1.37$ & $p=0.17$ \\
\hline tCOD (ua. $\min ^{-1}$ ) & $9.98 \pm 2.64$ & $9.50 \pm 2.47$ & $10.34 \pm 2.44$ & $p=0.11$ \\
\hline hCOD (ua.min $\left.{ }^{-1}\right)$ & $0.65 \pm 0.31$ & $0.57 \pm 0.28$ & $0.59 \pm 0.35$ & $p=0.05$ \\
\hline tDEC (ua. $\mathrm{min}^{-1}$ ) & $2.18 \pm 0.48$ & $2.21 \pm 0.55$ & $4.07 \pm 3.54^{b, c}$ & $\mathrm{p}<0.01$ \\
\hline hDEC (ua.min ${ }^{-1}$ ) & $0.18 \pm 0.08$ & $0.18 \pm 0.09$ & $0.28 \pm 0.24^{b, c}$ & $\mathrm{p}<0.01$ \\
\hline tACC (ua. $\left.\min ^{-1}\right)$ & $2.25 \pm 0.61$ & $2.11 \pm 0.62$ & $2.26 \pm 0.71$ & $p=0.13$ \\
\hline hACC (ua. $\mathrm{min}^{-1}$ ) & $0.38 \pm 0.16^{a}$ & $0.32 \pm 0.16$ & $0.33 \pm 0.20$ & $p=0.02$ \\
\hline tJUMP (ua.min ${ }^{-1}$ ) & $1.55 \pm 0.42$ & $1.56 \pm 0.42$ & $1.67 \pm 0.52$ & $p=0.35$ \\
\hline hJUMP (ua.min ${ }^{-1}$ ) & $0.19 \pm 0.11$ & $0.20 \pm 0.12$ & $0.22 \pm 0.13$ & $p=0.30$ \\
\hline
\end{tabular}

Note. a, significant differences EBA vs U18L; b, significant differences EBA vs U18T; c, significant differences U18L vs U18T. PL is Player Load per player; tCODmin is the total number of movements to the right / left; hCOD is the number of movements to the right / left above the high-intensity threshold $\left(>3 \mathrm{~m} \mathrm{x} \mathrm{s}^{-2}\right)$; tDEC is the total number of decelerations; hDEC is the number of high-intensity decelerations $\left(<-3 \mathrm{~m} \mathrm{x} \mathrm{s}^{-2}\right)$; tACC is the total number of accelerations; hACC is the number of high-intensity accelerations ( $>3 \mathrm{~m} \mathrm{x} \mathrm{s}^{-2}$ ); tJUMP is the total number of jumps; and hJUMP is the number of jumps above $40 \mathrm{~cm}$. Bold letters highlight the higher value of the three competition levels.

Figure 1 presents ES for all variables, comparing all competitions. Results of the EBA and U18L comparison showed small ES on hCOD ( $p>0.05)$, tACC ( $p>0.05)$, and hACC ( $p$ $=0.02)(\mathrm{EBA}>\mathrm{U} 18 \mathrm{~L})$.

The comparison between U18T and EBA is displayed in the medial part of Figure 1. In this case, small ES are shown in the PL ( $p>0.05), \operatorname{hDEC}(\mathrm{p}>0.05)$, and JUMP $(\mathrm{p}>0.05)$ variables $(\mathrm{U} 18 \mathrm{~T}>\mathrm{EBA})$. $\mathrm{tDEC}$ was the only variable that showed a significant moderate effect in favour of U18T ( $\mathrm{p}<$ 0.01 ); in contrast, a small non-significant difference was found in hACC between the competition in favour of EBA.

In the lowest part of Figure 1, results from a comparison between the two U18 competitions are shown. All variables expressed higher demands in U18T with a significant moderate $\mathrm{ES}$ in the $\mathrm{tDEC}$ variable. In addition, PL, tCOD, and hDEC presented small ES compared to U18L. 
PLAYING LEVELS

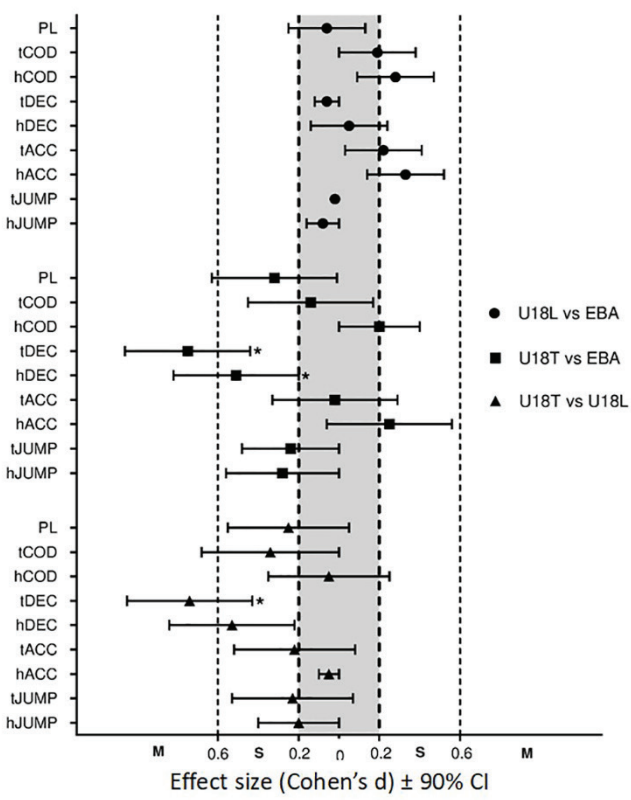

Figure 1. Effect size (Cohen's d) with $90 \%$ confidence interval on the differences between the three competitions (EBA, U18L and U18T). PL is Player Load per player; tCODmin is the total number of movements to the right / left; hCOD is the number of movements to the right / left above the high-intensity threshold $\left(>3 \mathrm{~m} \mathrm{x} \mathrm{s}^{-2}\right) ; \mathrm{tDEC}$ is the total number of decelerations; hDEC is the number of high-intensity decelerations $\left(<-3 \mathrm{~m} \mathrm{x} \mathrm{s}^{-2}\right)$; tACC is the total number of accelerations; hACC is the number of highintensity accelerations ( $\left.>3 \mathrm{~m} \mathrm{x} \mathrm{s}^{-2}\right)$; tJUMP is the total number of jumps; hJUMP is the number of jumps above $40 \mathrm{~cm}$.

\section{Discussion}

This study aimed to describe and compare the physical demands of the same U18 players in three different basketball competitions during the same season. This is the first investigation that examines the differences in the external load demands of different competitions in the same basketball players using micro-technology to the authors' knowledge. The main conclusion of the study is that competition with teams of international level (U18T) causes higher physical requirements, expressed in most variables (except for hCOD and hACC), than regional competitions (U18L and EBA senior level).

The higher level U18 players who belonged to academies of professional teams showed higher anthropometric values and a better physical condition (Vernillo et al., 2012). These differences were revealed during matches with teams of international calibre, requiring a higher physical level. Additionally, players with better physical condition showed their capacities during the match, increasing the distance travelled at high speed (Abdelkrim et al., 2010).

Differences between international players and national players have been studied. The former expressed a higher percentage of maximum heart rate and a higher blood lactate concentration during international competitions (Rodriguez-Alonso et al., 2003). However, the players included in the study corresponded to two different groups. Nevertheless, the anthropometric characteristics of participants in the present study are similar to U18 European players (Jelicic et al., 2002; Vázquez-Guerrero et al., 2019). Consequently, it could be assumed that the competitive level of the analysed team corresponds to the physical demands of the international tournament (U18T), with the U18L level being below its potential capacities.

The Spanish EBA league is the fourth senior age category within Spanish basketball. Despite this, many junior players compete in this league as a preliminary step in their sports development, seeking later professionalism in basketball. Nevertheless, only the hCOD and hACC variables presented higher values in this category compared to U18L and U18T. Both variables were expressed in their magnitude of high intensity. This result can be explained by the fact that players can compete in senior years in the EBA league, with stronger and faster players playing basketball of greater intensity than the U18 categories.

In the U18L, a greater number of tCOD and tACC movements were found. These results are in line with a recent study showing that U18 players express a higher frequency in the total number of ACC and DEC compared to elite players (Trapero et al., 2020). However, it is important to highlight that the mentioned study used two different groups of players that competed at two different levels, which can hamper possible comparisons.

Regarding high-intensity actions and their intermittence, the values of high-intensity actions tend to increase as the level of the league increases (Ferioli et al., 2020; Scanlan et al., 2011). One explanation for this phenomenon is that, at a higher level, players show a more efficient technical-tactical behaviour compared to young or sub-elite players. High-level players cover less distance at medium speeds and show a lower frequency in the number of actions (Zhang et al., 2017; Petway et al., 2020). Furthermore, this technical-tactical efficiency during basketball matches is a qualitative indicator of performance (Sampaio et al., 2015). However, the EBA league is a non-professional league; therefore, the anthropometric profile and the player's level of physical condition may not demand a high external load in most variables compared to international U18T.

Another point to highlight is the different competitive format of the analysed competitions. While the EBA and U18L matches were played during the in-season period (i.e., one game per week), the four U18T games were congested in a 
three-day period. Instead, the highly competitive density, the external load values of most variables were higher in U18T than in EBA and U18L. These results show that accumulated fatigue in tournament-based competition could not be a major limitation for physical performance during official basketball tournaments (Moreira et al., 2012). Indeed, the context (opponents, supporters, motivation, etc.) might favour the levelling of physical demands during competition.

In the end, we must acknowledge certain limitations of this study. First, there are no internal load variables included. Nevertheless, although we did not analyse how the external load influences the players' internal responses, the external load only showed small variations in the three different competitions. Second, this study shows only average values of the selected variables, which may underestimate the most demanding scenarios during the competition. Finally, future research should incorporate the analysis of the emotional and psychological component and how this influences the physical demands when facing matches in one competition or another

In conclusion, the present study describes how different competition levels suppose different external load stimuli in the same players with the same game model. Therefore, basketball coaches and strength and conditioning specialists must consider the level of competition at which players are incorporated. This must be based on the physical characteristics and the need to develop their path to professionalism. This information must be used to compete at the optimal level, where players can express the greatest possible physical demands and promote their development.

\section{References}

Abdelkrim, N.B., Castagna, C., Jabri, I., Battikh, T., El Fazaa, S., \& El Ati, J. (2010). Activity profile and physiological requirements of junior elite basketball players in relation to aerobic-anaerobic fitness. The Journal of Strength of Conditioning Research, 24(9), 2330-2342. doi: 10.1519/ JSC.0b013e3181e381c1

Batterham, A. M., y Hopkins, W. G. (2006). Making inferences about magnitudes. International Journal of Sports Physiology and Performance, 1(1), 50-57. doi: 10.1123/ ijspp.1.1.50

Berry, J., Abernethy, B., \& Côté, J. (2008). The contribution of structured activity and deliberate play to the development of expert perceptual and decision-making skill. Journal of Sport and Exercise Psychology, 30(6), 685-708. doi: 10.1123/jsep.30.6.685

Calleja-González, J., et al (2016). The Spanish "Century XXI" academy for developing elite level basketballers: design, monitoring and training methodologies. The Physician and Sports Medicine, 44(2), 148-157. doi 10.1080/00913847.2016.1168270

Carter, J. L. (1982). Body composition of Montreal Olympic athletes. In Physical structure of Olympic athletes, (16), 107 116.

Conte, D., Favero, T. G., Niederhausen, M., Capranica, L., \& Tessitore, A. (2017). Determinants of the effectiveness of fast break actions in elite and sub-elite Italian men's basketball games. Biology of sport, 34(2), 177. doi: 10.5114/ biolsport.2017.65337

Ericsson, K. A., Krampe, R. T., \& Tesch-Römer, C. (1993). The role of deliberate practice in the acquisition of expert performance. Psychological Review, 100(3), 363.
Ferioli, D., Schelling, X., Bosio, A., La Torre, A., Rucco, D., \& Rampinini, E. (2020). Match activities in basketball games: comparison between different competitive levels. The Journal of Strength \& Conditioning Research, 34(1), 172182. doi: 10.1519/JSC.0000000000003039

Fox, J. L., Stanton, R., Sargent, C., O'Grady, C. J., \& Scanlan, A. T. (2019). The Impact of Contextual Factors on Game Demands in Starting, Semiprofessional, Male Basketball Players. International Journal of Sports Physiology and Performance, 15(4), 450-456. doi: 10.1123/ijspp.2019-0203

Fox, J., Green, J., \& Scalan, A. (2021). Not all about the effort? A comparison of playing intensities during winning and losing game quarters in basketball. International journal of sports physiology and performance, 3(3), 1-4. doi: 10.1123/ ijspp.2020-0448

Harriss, D. J. and Atkinson, G. (2015) Ethical standards in sport and exercise science research: 2016 update. International Journal of Sports Medicine 36(14), 1121-1124

Jelicic, M., Sekulic, D., \& Marinovic, M. (2002). Anthropometric characteristics of high level European junior basketball players. Collegium Antropologicum, 26, 69-76.

Lee, R. C., Wang, Z., Heo, M., Ross, R., Janssen, I., \& Heymsfield, S. B. (2000). Total-body skeletal muscle mass: development and cross-validation of anthropometric prediction models. The American journal of clinical nutrition, 72(3), 796-803. doi: 10.1093/ajcn/72.3.796

Luteberget, L. S., Spencer, M., \& Gilgien, M. (2018). Validity of the Catapult ClearSky T6 local positioning system for team sports specific drills, in indoor conditions. Frontiers in Physiology, 9, 115. doi: 10.3389/fphys.2018.00115

Moreira, A., Crewther, B., Freitas, C. G., Arruda, A. F., Costa, E. C., \& Aoki, M. S. (2012). Session RPE and salivary immune-endocrine responses to simulated and official basketball matches in elite young male athletes. Journal of Sports Medicine and Physical Fitness, 52(6), 682-687.

Newell, A., \& Rosenbloom, P. S. (1981). Mechanisms of skill acquisition and the law of practice. Cognitive skills and their acquisition, 1(1981), 1-55.

Nicolella, D. P., Torres-Ronda, L., Saylor, K. J., \& Schelling, X. (2018). Validity and reliability of an accelerometer-based player tracking device. PloS One, 13(2), e0191823. doi: 10.1371/journal.pone.0191823

Petway, A. J., Freitas, T. T., Calleja-González, J., Medina Leal, D., \& Alcaraz, P. E. (2020). Training load and match-play demands in basketball based on competition level: A systematic review. PloS one, 15(3), e0229212. doi: 10.1371/ journal.pone.0229212

Rodriguez-Alonso, M., Fernandez-Garcia, B., PerezLandaluce, J., \& Terrados, N. (2003). Blood lactate and heart rate during national and international women's basketball. Journal of Sports Medicine and Physical Fitness, 43(4), 432.

Salazar, H., Castellano, J., \& Svilar, L. (2020). Differences in external load variables between playing positions in elite basketball match-play. Journal of Human Kinetics, 75(1), 257-266. doi: 10.2478/hukin-2020-0054

Sampaio, J., McGarry, T., Calleja-González, J., Sáiz, S. J., Schelling, X., \& Balciunas, M. (2015). Exploring game performance in the National Basketball Association using player tracking data. PloS one, 10(7), e0132894. doi: 10.1371/journal.pone.0132894

Scanlan, A., Dascombe, B., \& Reaburn, P. (2011). A comparison 
of the activity demands of elite and sub-elite Australian men's basketball competition. Journal of Sports Sciences, 29(11), 1153-1160. doi: 10.1080/02640414.2011.582509

Sotiriadou, P., \& Shilbury, D. (2013). Sport development in high performance sport: The process of attracting, retaining and nurturing athletes. In managing high performance sport (pp. 171-190). Routledge.

Stojanovic, E., Stojiljkovic, N., Scanlan, A. T., Dalbo, V. J., Berkelmans, D. M., \& Milanovic, Z. (2018). The activity demands and physiological responses encountered during basketball match-play: A systematic review. Sports Medicine, 48(1), 111-135. doi: 10.1007/s40279-017-0794-Z

Svilar, L., Castellano, J., Jukic, I., \& Casamichana, D. (2018). Positional differences in elite basketball: selecting appropriate training-load measures. International journal of sports physiology and performance, 13(7), 947-952. doi: 10.1123/ijspp.2017-0534.

Trapero, J., et al. (2019). Comparison of the Movement
Characteristics Based on Position-Specific between SemiElite and Elite Basketball Players. Revista de Psicología del Deporte, 28(3), 0140-145.

Vázquez-Guerrero, J., Jones, B., Fernández-Valdés, B., Moras, G., Reche, X., \& Sampaio, J. (2019). Physical demands of elite basketball during an official U18 international tournament. Journal of Sports Sciences, 37(22), 2530-2537. doi: 10.1080/02640414.2019.1647033

Vernillo, G., Silvestri, A., \& La Torre, A. (2012). The yo-yo intermittent recovery test in junior basketball players according to performance level and age group. The Journal of Strength \& Conditioning Research, 26(9), 2490-2494. doi: 10.1519/JSC.0b013e31823f2878.

Zhang, S., Lorenzo, A., Gómez, M. A., Liu, H., Gonçalves, B., \& Sampaio, J. (2017). Players' technical and physical performance profiles and game-to-game variation in NBA. International Journal of Performance Analysis in Sport, 17(4), 466-483. doi:10.1080/24748668.2017.1352432 